\title{
Emerging Use of Early Health Technology Assessment in Medical Product Development: A Scoping Review of the Literature
}

\author{
Maarten J. IJzerman ${ }^{1,2} \cdot$ Hendrik Koffijberg ${ }^{1} \cdot$ Elisabeth Fenwick $^{3}$ • \\ Murray Krahn ${ }^{4}$
}

Published online: 21 April 2017

(C) The Author(s) 2017. This article is an open access publication

\begin{abstract}
Early health technology assessment is increasingly being used to support health economic evidence development during early stages of clinical research. Such early models can be used to inform research and development about the design and management of new medical technologies to mitigate the risks, perceived by industry and the public sector, associated with market access and reimbursement. Over the past 25 years it has been suggested that health economic evaluation in the early stages may benefit the development and diffusion of medical products. Early health technology assessment has been suggested in the context of iterative economic evaluation alongside phase I and II clinical research to inform clinical trial design, market access, and pricing. In addition, performing early health technology assessment was also proposed at an even earlier stage for managing technology portfolios. This scoping review suggests a generally accepted definition of early health technology assessment to be "all methods used to inform industry and other stakeholders about the potential value of new medical products in development, including methods to quantify and manage uncertainty". The present review also aimed to identify recent published empirical studies employing an early-stage assessment of a medical product. With most included studies carried out to support a
\end{abstract}

Maarten J. IJzerman

m.j.ijzerman@utwente.nl

1 Department of Health Technology and Services Research, University of Twente, Enschede, The Netherlands

2 Evidence Synthesis and Health Economics Unit, Luxembourg Institute of Health, Strassen, Luxembourg

3 ICON plc., Oxford, UK

4 Toronto Health Economics and Technology Assessment Collaborative, University of Toronto, Toronto, ON, Canada market launch, the dominant methodology was early health economic modeling. Further methodological development is required, in particular, by combining systems engineering and health economics to manage uncertainty in medical product portfolios.

\section{Key Points for Decision Makers}

The use of pharmacoeconomics in the early stages of clinical evidence development has been proposed since the mid-1990s. Since then, early health technology assessment has emerged and frequently applied to support medical product development and market access.

The most frequently used methodology in early health technology assessment is early-stage (or iterative) health economic modeling including headroom analysis.

Future developments should focus on the integration of early health economic models with systems engineering approaches, such as multi-criteria decision analysis and optimization methods, to actually support decisions in medical product development.

\section{Introduction}

Over the last two decades, there has been an increasing interest in using early-stage models to inform product development, market access, and pricing. The use of earlystage health economic models is relevant to inform 
decisions on the commercial viability of new medical technologies, and it thus allows companies to stop further development if results suggest that the product is unlikely to be successful, in other words 'fail fast, fail cheap'.

Although early-stage health economic modeling has been around for some time, different definitions are used. From a historical perspective, the iterative use of health economic evaluation along the product development pathway was first mentioned in the mid-1990s by Mauskopf et al. [1], Sculpher et al. [2], Grabowski [3], and Terrés [4]. While Mauskopf et al. [1] urged for early involvement of health economics and outcomes research (HEOR) in the clinical evidence development strategy, Sculpher et al. [2] proposed a model to collect health economic evidence starting in the early stages of clinical evidence development, including a systematic evaluation of costs associated with the intervention and early-stage health economic models. Until then, most publications on early-stage health economic modeling were on drug development. It was 2006 before the first papers presenting an early-stage health economic model in medical devices were published. Dong and Buxton published an early-stage Markov model with a probabilistic sensitivity analysis for a knee replacement procedure [5], van Til et al. published an early-stage model on the use a neural prosthesis for post-stroke shoulder pain [6], and Hjelmgren et al. published a study on cell replacement therapy in Parkinson's disease [7].

In 2008, Hartz and John published an extensive review including more than 1000 papers with a final set of 83 including empirical studies, 56 in pharmaceuticals and 27 in medical devices [3,8]. Although their paper does not give the details on the included empirical studies, they summarized the benefits of early-stage modeling as supporting: strategic research and development (R\&D) decision making, pre-clinical preliminary market assessments, go/no-go decisions, identification of potentially successful projects, development of future trial design, and assessment of future reimbursement and pricing $[4,8]$.

While the early work on early-stage health economic models mainly comprised health economic evidence collection in early stages of clinical drug development $[1,5,9]$, Miller was the first to broaden the scope [10], followed by Vallejo-Torres et al. [11], Pietzsch and PatéCornell [12], and IJzerman and Steuten [13]. Miller extended the role of health economic modeling in the early stages of drug development, to a range of other methods that are used to manage product portfolios such as clinical trial simulation, options pricing, and value of information. Pietzsch was the first to introduce early health technology assessment (HTA) as a systems engineering approach to support companies to make internal decisions about medical device development [12]. IJzerman further conceptualized early HTA by introducing HTA in (early) translational research, by providing an overview of the key methodologies used as well as the various stakeholders to be informed at different decision gates [13]. While the former papers suggest that early HTA is about quantitative health economic methods to manage product portfolios, Rogowski et al. extended the meaning of early HTA by introducing the value chain in the recent book chapter on translational health economics. They identified at least three different stages where health economics can contribute to the translational value chain; at the initiation of a new process of development, during the process of $R \& D$ by health economic evidence generation, and finally in the implementation by working toward managed-entry arrangements [14]. In addition, Levin also describes early evaluation as a mechanism of risk sharing in the development of evidence on costs and effects of the new technology. He suggests HTA was originally developed for technologies that had passed regulatory approval, and proposes single studies that harmonize regulatory and coverage decisions [15].

Another finding is the increasing interest in the early HTA of medical devices. While most of the early work is about informing drug development, there has been a rapid increase in studies evaluating medical devices since 2006. This is likely mainly owing to the global trend to build strong regional medical technology innovation clusters with support of (local) governments. It is often recognized that medical technology success greatly depends on the value created to the health system in terms of patient outcomes, convenience, or sustainability of care. There are many examples of such innovation clusters in Europe and Canada, but some of them have also formally connected to academic HTA research groups such as MARS-Excite in Ontario (http://www. marsdd.com), Medical Valley in Erlangen (http://www. medical-valley-emn.de), Oncotyrol in Austria (http:// www.oncotyrol.at/en/), Center for Translational Molecular Medicine in Eindhoven (http://www.ctmm.org), and Health Valley (http://healthvalley.nl).

The primary objective of this article is to review the historical context of early HTA, and to identify recently published empirical studies. This review is structured into four different sections. The article first starts by framing the context of early HTA based on the different viewpoints and definitions used, this is followed by a literature update presenting studies published between 2013 and 2016. The third and main part of the article is an overview of the different methods used. The article concludes with a discussion of future developments in early HTA in valuebased health systems and personalized healthcare in particular. 


\section{Early Health Technology Assessment in the Context of Translational Research}

Most of the initial work on early HTA was in the context of iterative economic evaluation alongside clinical evidence development strategies. Figure 1 presents an overview of studies that introduced the use of health economic evaluation alongside drug development, later also referred to as iterative use of health economic evaluation. The figure shows that the initial papers were published from the mid-1990s until 2001 and proposed the collection of health economic evidence alongside clinical trials in stage I and II $[1,3,4,9,16,17]$.

In all these uses of the term early HTA, the medical product, which often is about drug development, is ready for testing in clinical trials, which means the reference to 'early' in this case reflects the uncertainty in the clinical evidence and the mechanisms to reduce or mitigate uncertainty in evidence development. This may even include decisions to stop further clinical investigation. Several examples of such iterative health economic modeling were published in the past, demonstrating, for instance, the value of additional research [18].
Ten years after the introduction of iterative use of health economic modeling in drug development, the first empirical early-stage health economic models of medical devices and advanced therapy products were published [5-7]. It is at this point in time that another meaning of early HTA started to emerge. According to Pietzsch and Paté-Cornell, early HTA is used to inform manufacturers and investors about the design and management of a technology, as well as regulatory and reimbursement strategy [12]. They suggest the HTA process may also have an impact on the medical device design, specifications, and thus performance. This wider definition is the focus of most of the recent work on early HTA. IJzerman and Steuten distinguish early HTA in the context of informing health policy and industry, respectively, and urge for more clarity about the definition of early HTA [13]. In their paper, they identified the different decision gates where HTA may be beneficial, and distinguished different objectives of the assessment such as informing $\mathrm{R} \& \mathrm{D}$, market access, and health policy. Although early assessment may support revenue maximization decisions in companies, it clearly emerged from a societal need to justify public investments in $R \& D$ as a result of the growing number of public-private partnerships [19].

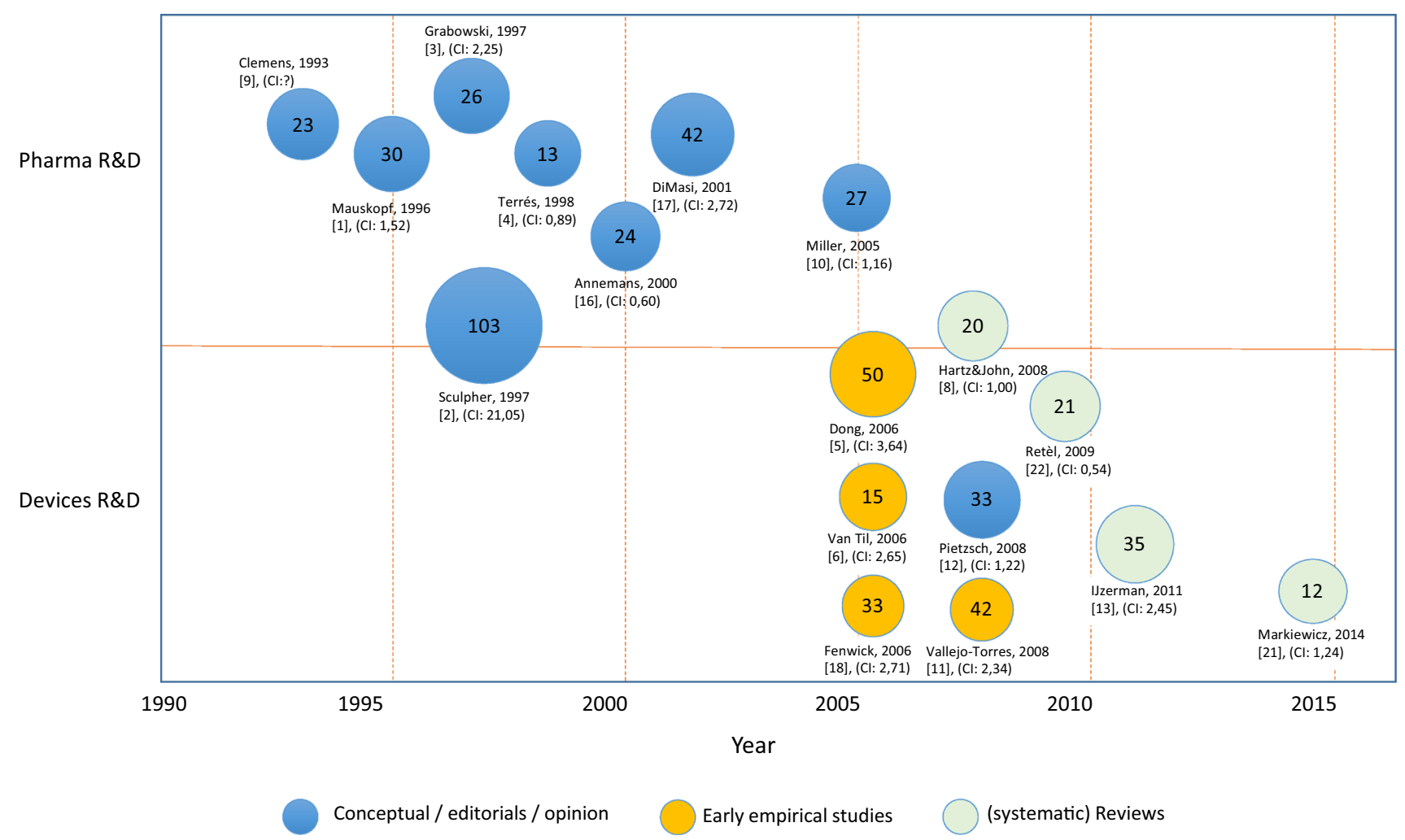

Fig. 1 Scopus results of highly cited conceptual, empirical, and review papers presenting iterative economic evaluation in drug and medical device development. The figure presents first author and number of Scopus citations until April 2017. Balloon size depicts the number of citations. [1] is the reference number, where (CI 2,45) represents the Field-Weighted Citation Index. A Field-Weighted Citation Index higher than 1,0 indicates the paper is more cited than expected according to the average. Note that fields may change for the included papers. $R \& D$ : Research \& Development 


\section{Systematic Scoping Literature Search}

One purpose of this article is to give an update on current developments in early HTA with the intention to scope the actual use of early HTA. As such, a two-step citation analysis was carried out using previously published key references and followed by hand searching in Scopus. This strategy was required to analyze the development of the field, and it also maximizes the search output as early HTA is not yet a well-defined field of research with clear keywords and Medical Subject Headings. The search was meant to be an update of previous reviews and thus limited to the time frame between September 2013 and April 2017 because the previous 2006-13 time window was well covered by other reviews $[8,20,21]$.

The citation analysis started with a systematic search of the literature for keywords using MEDLINE and Scopus databases. The following keywords were used in different combinations 'early HTA', 'Health Technology Assessment', 'HTA', 'R\&D, 'commercialization', and 'product development' as well as for specific methodologies such as 'Headroom', 'patient preference', 'multi-criteria', and 'Markov model' (see Appendix). All references were then crosschecked for additional papers using MEDLINE and Scopus.

After reviewing the title and abstract of all identified papers, 38 studies were finally selected for further analysis based on the selection criteria. After reading all 38 included papers, another selection was made to ensure the papers actually discussed, proposed, or applied a methodology to inform decisions in an early stage of product development. Finally, 22 case studies published between 2013 and 2016 were included (see Appendix for details of included and excluded papers).

\section{Definitions and Methods Used in Early Health Technology Assessment}

\subsection{Definitions and Methods Used in Previously Published Reviews}

Over the past 10 years, four systematic reviews have been published on early health economic modeling and/or early HTA. Each of them is discussed here with a specific objective to compare the definition of early HTA that was used and the methodologies that were identified in the reviews.

In 2008, Hartz and John published the first comprehensive review on early HTA methods as part of the European Inno-HTA project [8]. Although the paper did not include a formal definition of early HTA, they suggested early HTA to be an economic evaluation in early stages of product development, mainly to provide the manufacturer with information about the future commercial viability of the product. They read more than 1000 abstracts and finally included 83 (56 drugs and 27 medical devices) empirical studies that met the inclusion criteria. In addition to the 83 empirical studies, they found 71 methodological papers [8]. The search revealed that key methodologies are early health economic modeling, Bayesian methods, and clinical trial simulation.

Retèl et al. [22] performed a review of early technology assessment of nanotechnologies in cancer, including nanoparticles and other therapeutic agents based on nanotechnology principles. While they also refer to early technology assessment, they mainly reviewed from a policy perspective and thereby referred to the field of constructive technology assessment. Their initial search only found one (out of 91) paper that performed a technology assessment. From an extended search they concluded that although technology assessments do include safety and efficacy, health economic issues are not considered [22].

IJzerman and Steuten published a narrative review on methods for early HTA of medical devices [13]. Although they did not present a definition of early HTA, they suggested there is a need to inform decisions in earlier stages of product development. In addition, they suggested early HTA can also be useful to inform about public investments and urge for more specificity while using the term early HTA with respect to the type of decision, the stakeholders involved, and the actual decision maker. They presented a wide range of methods used for an early assessment, such as early health economic modeling, real-options analysis, clinical trial simulation, headroom, value-of-information, multi-criteria decision analysis (MCDA), and discrete-choice experiments.

In 2014, a fourth systematic literature review was published presenting specific methodologies in the early assessment of medical devices [21]. This review searched for papers published between 1996 and 2013. They suggest that early assessment should be defined as the assessment of the value of a new medical device at the time when investment decisions are made. They herewith relax the assumption that early HTA is only relevant for manufacturers. Of 1961 papers identified, 113 were included of which 82 were empirical studies. Compared with Hartz and John [8], the review was limited to medical devices. The review has identified a number of qualitative and quantitative methodologies including early health economic models, headroom, value of information, real-options analysis, technology road mapping, scenario analysis, MCDA, conjoint analysis, and different qualitative methods such as interviews and expert panels.

\subsection{Proposed Definition of Early Health Technology Assessment}

Informed by the various definitions proposed for early HTA in the literature, we suggest that early HTA be 
Fig. 2 Overview of papers reporting an early-stage assessment during product development (2013-17). Studies are arbitrarily categorized into:

(1) headroom $(n=4)$ is used to estimate the maximum sales prices based on the relative value added to society; (2) early-stage modeling $(n=12)$ is considered as health economic modeling in early stages of development where there are (relatively) many evidence gaps; and (3) multicriteria decision analysis (MCDA) and stakeholder elicitation $(n=6)$ are those methods that either elicit unknown priors or opinions from experts where MCDA is used to provide actual decision support by drafting and quantifying development scenarios. For a full list of references see the Appendix

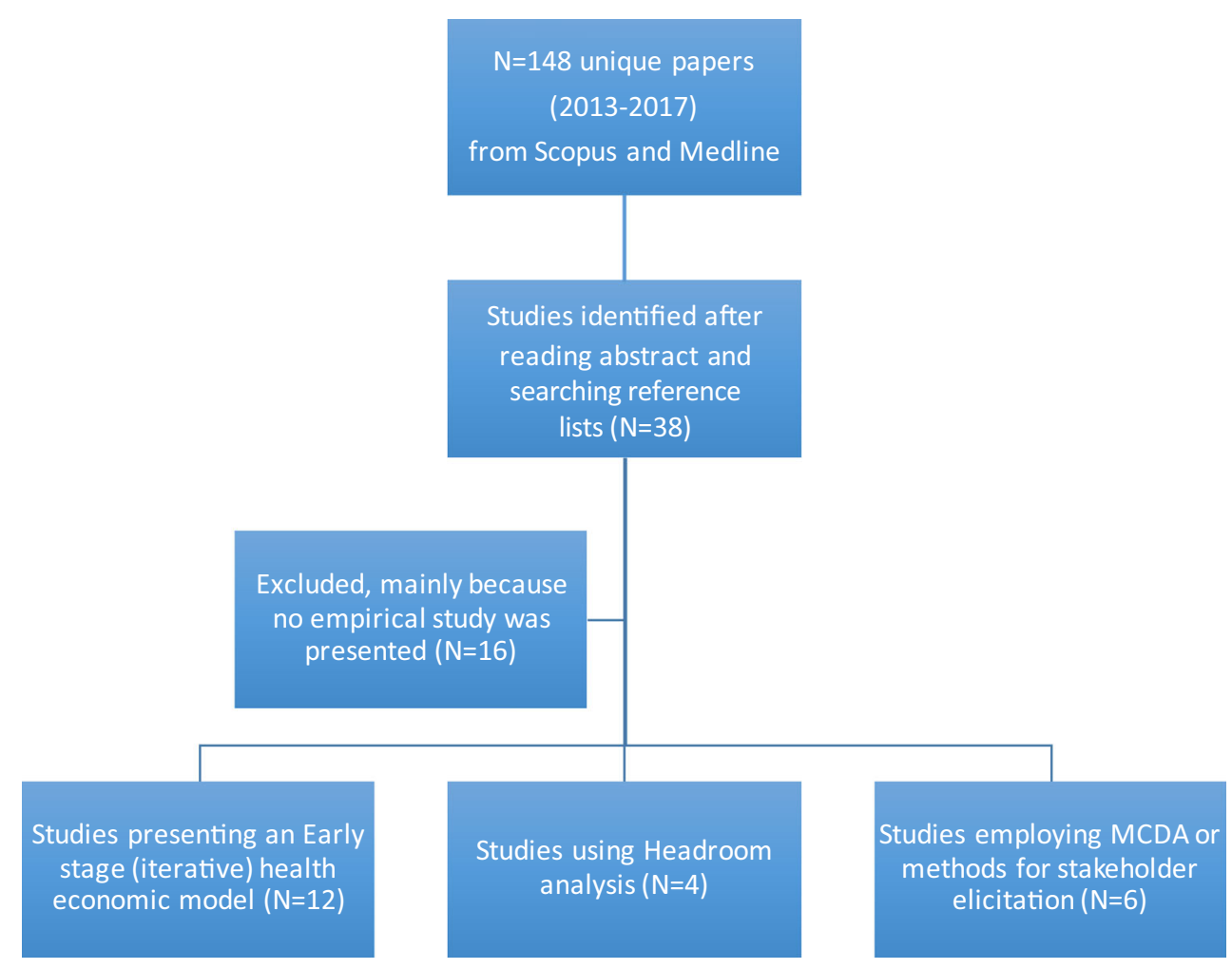

defined as "all methods used to inform industry and other stakeholders about the potential value of new medical products in development, including methods to quantify and manage uncertainty". There are some important implications of this definition. First, the definition assumes the industry is an important, but not the only, stakeholder. Second, the definition includes early HTA of medical products just before and also at the early stages of clinical use, while accepting that product development can continue after regulatory approval. Third, early HTA not only includes early-stage health economic modeling, but also broadens the scope to a range of methods that can be used to elicit stakeholder preferences, manage risk in technology portfolios, simulate clinical trials, and identify unmet needs. In agreement with previous work, five main reasons for conducting assessments in an early stage of product development were identified, i.e., strategic R\&D decisions, preclinical market assessment, portfolio decisions, clinical trial design, and market access and pricing strategies.

\section{Methods for Early Health Technology Assessment}

Although the aim of the search was to find novel methodologies used in early HTA, only a limited number of methods were actually found. The methods identified in 22 (out of 36) papers published between 2013 and 2016 were selected and categorized in three main groups: (1) headroom analysis; (2) early-stage health economic modeling; and (3) methods for elicitation of stakeholder preferences and MCDA (Fig. 2). From the 22 included papers, 11 studies presented an early-stage health economic model and those studies were reviewed in more detail to explore the actual methods used (Table 1).

\subsection{Headroom Method to Inform Product Development}

The headroom method was first used by Cosh [23] and then further developed and applied by, amongst others, Girling [24], Chapman [25], and Markiewicz [26]. The headroom determines the maximum reimbursable price of a product by using the prevailing willingness-to-pay thresholds. If an incremental gain in quality-adjusted life-years (QALYs) is expected, the gain represents a net-monetary value, which can be used to inform a commercial decision by estimating the return on investment. The headroom is very attractive for small and medium sized enterprise (SMEs) and other investors because of the requirement for data and ease of calculation. The method was first introduced by Cosh et al. and McAteer et al. in the case of tissue engineering, and three more recent publications presented different cases using headroom [23, 27]. Markiewicz et al. used the headroom method and return on investment to inform companies about five medical devices in development [26]. 
Table 1 Detailed overview of 11 empirical studies that specifically presented an early health economic model $(n=9)$ using decision trees or Markov state-transition models including headroom analysis

\begin{tabular}{|c|c|c|c|c|c|c|}
\hline References & Intervention & R\&D stage & Headroom & Model & $\begin{array}{l}\text { Expert } \\
\text { elicitation }\end{array}$ & Uncertainty \\
\hline $\begin{array}{l}\text { Cao et al. } \\
\text { [47] }\end{array}$ & $\begin{array}{l}\text { Point-of-care-test at } \\
\text { home/cardiology }\end{array}$ & Market launch & $\begin{array}{l}\text { Yes, } \\
\text { probability } \\
\text { distribution }\end{array}$ & Markov model & $\begin{array}{l}\text { Yes, probability } \\
\text { elicitation } \\
(N=3)\end{array}$ & $\begin{array}{l}\text { Monte Carlo } \\
\text { simulation, } \\
\text { distributions }\end{array}$ \\
\hline $\begin{array}{l}\text { Retel et al. } \\
\text { [29] }\end{array}$ & $\begin{array}{l}\text { 70-gene expression profile: } \\
\text { development of paraffin } \\
\text { based test }\end{array}$ & $\begin{array}{l}\text { R\&D decision to } \\
\text { develop 70G- } \\
\text { PAR }\end{array}$ & No & Markov model & $\begin{array}{l}\text { No, } \\
\text { assumptions } \\
\text { made based } \\
\text { on reference } \\
\text { data }\end{array}$ & $\begin{array}{l}\text { Simulations and VOI } \\
\text { analysis to determine } \\
\text { value of further } \\
\text { development and } \\
\text { research }\end{array}$ \\
\hline $\begin{array}{l}\text { Koerber } \\
\text { et al. [30] }\end{array}$ & $\begin{array}{l}\text { Cartilage defects in knee: new } \\
\text { matrix-cultivated } \\
\text { chrondrocytes m-ACI) }\end{array}$ & $\begin{array}{l}\text { Determine value } \\
\text { and pricing }\end{array}$ & No & $\begin{array}{l}\text { Deterministic, } \\
\text { decision tree }\end{array}$ & $\begin{array}{l}\text { No, } \\
\text { assumptions } \\
\text { on costs and } \\
\text { outcomes } \\
\text { based on } \\
\text { scenarios }\end{array}$ & $\begin{array}{l}\text { Deterministic } \\
\text { sensitivity analysis of } \\
\% \text { additional } \\
\text { cartilage (effects) }\end{array}$ \\
\hline $\begin{array}{l}\text { Miquel- } \\
\text { Cases et al. } \\
{[32]}\end{array}$ & $\begin{array}{l}\text { BRCAl-like test to detect triple } \\
\text { negative breast cancer }\end{array}$ & $\begin{array}{l}\text { Inform clinicians } \\
\text { and R\&D } \\
\text { about effect of } \\
\text { BRCA1 testing }\end{array}$ & No & Markov model & $\begin{array}{l}\text { No, based on } \\
\text { clinical trial } \\
\text { data }\end{array}$ & $\begin{array}{l}\text { One-way deterministic } \\
\text { sensitivity, threshold } \\
\text { and probabilistic } \\
\text { analysis (CEAC) }\end{array}$ \\
\hline $\begin{array}{l}\text { Brandes } \\
\text { et al. [31] }\end{array}$ & Vascular closure device & $\begin{array}{l}\text { Hypothetical } \\
\text { product }\end{array}$ & No & $\begin{array}{l}\text { Deterministic, } \\
\text { decision tree }\end{array}$ & No & $\begin{array}{l}\text { One-way sensitivity } \\
\text { analysis and tornado } \\
\text { diagram }\end{array}$ \\
\hline $\begin{array}{l}\text { de Windt } \\
\text { et al. [34] }\end{array}$ & $\begin{array}{l}\text { Regenerative medicine for } \\
\text { articular cartilage repair } \\
(\mathrm{ACI})\end{array}$ & Premarket & $\begin{array}{l}\text { Yes, } \\
\text { headroom } \\
\text { point } \\
\text { estimates }\end{array}$ & $\begin{array}{l}\text { Decision tree } \\
\text { with tree } \\
\text { options }\end{array}$ & No & $\begin{array}{l}\text { One-way sensitivity } \\
\text { analysis and tornado } \\
\text { diagram }\end{array}$ \\
\hline $\begin{array}{l}\text { Buisman } \\
\text { et al. [38] }\end{array}$ & $\begin{array}{l}\text { Four diagnostic strategies } \\
\text { (MRI, IL-6, B-cell } \\
\text { expression and genetic } \\
\text { assays) in patients suspected } \\
\text { of having RA }\end{array}$ & $\begin{array}{l}\text { Early stage } \\
\text { clinical } \\
\text { research, tests } \\
\text { are available }\end{array}$ & Yes & $\begin{array}{l}\text { Decision tree } \\
\text { with patient- } \\
\text { level state } \\
\text { transition } \\
\text { model }\end{array}$ & No & $\begin{array}{l}\text { Deterministic and } \\
\text { probabilistic } \\
\text { sensitivity analysis }\end{array}$ \\
\hline $\begin{array}{r}\text { Kolominsky } \\
\text { et al. [36] }\end{array}$ & $\begin{array}{l}\text { Implementation scenarios for } \\
\text { pulmonary artery pressure in } \\
\text { heart failure patients }\end{array}$ & $\begin{array}{l}\text { Implementation } \\
\text { of new device } \\
\text { to guide health } \\
\text { services } \\
\text { planning }\end{array}$ & No & $\begin{array}{l}\text { Systems } \\
\text { dynamics } \\
\text { and discrete- } \\
\text { event } \\
\text { simulation }\end{array}$ & No, trial based & $\begin{array}{l}\text { Deterministic } \\
\text { sensitivity analysis }\end{array}$ \\
\hline $\begin{array}{l}\text { Luime et al. } \\
\text { [35] }\end{array}$ & $\begin{array}{l}\text { Four diagnostic strategies } \\
\text { (MRI, IL-6, B-cell } \\
\text { expression and genetic } \\
\text { assays) as an add-on test in } \\
\text { patients with RA }\end{array}$ & $\begin{array}{l}\text { Early stage } \\
\text { clinical } \\
\text { research, tests } \\
\text { are available }\end{array}$ & Yes & $\begin{array}{l}\text { Decision tree } \\
\text { for first year } \\
\text { after } \\
\text { diagnosis }\end{array}$ & No & $\begin{array}{l}\text { Deterministic } \\
\text { sensitivity analysis } \\
\text { and scenario analyses }\end{array}$ \\
\hline $\begin{array}{r}\text { Markiewicz } \\
\text { et al. [26] }\end{array}$ & Five diagnostic devices & Premarket & $\begin{array}{l}\text { Yes, and } \\
\text { return on } \\
\text { investment }\end{array}$ & $\begin{array}{l}\text { Headroom } \\
\text { point } \\
\text { estimate }\end{array}$ & $\begin{array}{l}\text { Qualitative } \\
\text { interviews }\end{array}$ & $\begin{array}{l}\text { Uncertainty not } \\
\text { addressed }\end{array}$ \\
\hline $\begin{array}{l}\text { Kip et al. } \\
\text { [45] }\end{array}$ & $\begin{array}{l}\text { Triple biomarker to exclude } \\
\text { nSTEMI leading to early } \\
\text { discharge }\end{array}$ & $\begin{array}{l}\text { Technology } \\
\text { available but } \\
\text { not used }\end{array}$ & Yes & Decision tree & $\begin{array}{l}\text { Yes, elicitation } \\
\text { of clinical } \\
\text { utility of test } \\
(N=10)\end{array}$ & $\begin{array}{l}\text { One-way } \\
\text { (probabilistic) } \\
\text { sensitivity analysis } \\
\text { with Tornado } \\
\text { diagram }\end{array}$ \\
\hline
\end{tabular}

$A C l$ autologous chondrocyte implantation, CEAC cost-effectiveness acceptability curve, $m$ - $A c l$ matrix assocated autologous chondrocyte implantation, MRI magnetic resonance imaging, nSTEMI non-ST elevated myocardial infarction, $R \& D$ research and development, $R A$ rheumatoid arthritis, VOI value of information

They suggest the headroom is forcing SMEs to think about the added value of their medical product instead of using the current cost-plus approach, which often is used to determine market prices. The cases show that it can be challenging to estimate the added value, usually expressed in QALYs. Chapman et al. [25] presented a study 
comparing the predicted headroom of 20 cases with the actual uptake by the National Health Service. They conclude that the positive predictive value for uptake was $86 \%$, meaning that uptake is very likely in cases with a favorable headroom. It should be said, however, that this applies to the nationally controlled UK health system. The original headroom method actually does not specifically address developmental uncertainty. In a recent paper, Girling et al. [24] encourage the use of headroom because it is fast and easy to undertake. Yet, they also acknowledged the issues with headroom when it comes to making a decision on a single numerical quantity in an early stage of development. There are multiple other issues to consider, such as the impact on the company's product portfolio, (technical) developmental uncertainties, and a range of other competitive measures. They therefore suggest working on methods that do incorporate distributions over future outcomes as well as on methods to improve the elicitation of beliefs by experts about future outcomes [24]. Incorporation of uncertainties over future outcomes and developmental uncertainty is close to real-options analysis, where future developmental scenarios are both identified and quantified as options-value [28].

\subsection{Early-Stage Health Economic Models}

In the search, nine different applications presenting an early-stage health economic model were identified [29-36, 45]. Three additional papers were excluded because they either extended an initial modeling study with longterm data or addressed a specific question about the value of additional research [37-39]. The applications that were evaluated included diagnostic tests for rheumatoid arthritis, a vascular closure device, tissue-engineered cartilage repair, a diagnostic test for stroke recurrence, and genomic profiling in breast cancer (Table 1). From the table, it can be seen that the majority of studies involve products that are either available for clinical trials or nearly available for market launch. No studies were found that evaluated specific devices or drug compounds in an early stage prior to the start of clinical trials. All case studies involved a health economic model using either a decision tree or state-transition approach, where uncertainty over future outcomes is either analyzed using a sensitivity analysis or reduced by eliciting expert beliefs over such outcomes. Both deterministic and probabilistic sensitivity analyses are used in the case studies. Deterministic sensitivity analysis allows further analysis of the main drivers of cost effectiveness in the model, which can be used to inform companies about design improvements. Probabilistic sensitivity analysis is frequently employed as part of a Bayesian framework and can be used to determine the value of additional research and thus prioritize further clinical evidence development.
A specific modeling approach was used by KolominskyRabas et al. [36]. They used dynamic simulation, i.e., systems dynamics and discrete-event simulation, to extrapolate the health and economic benefits of implementing a new monitoring device for patients with heart failure. Although the device is available, the modeling approach is new in its objectives to account for health systems dynamics and thus anticipate real-world effects.

Where other studies implemented modeling strategies comparing a new technology with current care, Djanatliev et al. suggested dynamic simulation models to extrapolate the effect of new medical technology implementation in a specific care pathway where a long-term foresight is required [40]. They specifically propose the methodology with respect to the design of medical devices where the decision to develop the new technology depends on the expected future use as well as context in which the technology is used. An example of this modeling approach is shown in the case of 'mobile stroke units', which aim to reduce the time to thrombolysis [36]. The authors suggest that, while other methods fail to account for future dynamics, systems modeling is a better approach. A potential disadvantage, however, is the relatively high data demands.

\subsection{Stakeholder Preference Elicitation and Multi- Criteria Decision Analysis}

A potentially promising methodology in early HTA is the use of choice models and MCDA for estimating the value of (future) interventions and to identify preferences for new medical products. By systematic collection of preferences for different stakeholder groups for a set of hypothetical new products, it is possible to estimate the relative value of new medical technologies. Different examples are published either to inform medical product development or health policy.

In addition, MCDA is another methodology used to support decisions in early stages of medical product development. In particular, MCDA has been proposed to support portfolio decisions where resources over a range of technologies are allocated based on future value and development risk [41]. At different points in the development, a product's value can be established for different stakeholders and used to support actual decision making [42].

One specific form of stakeholder elicitation is the use of belief elicitation methods to elicit unknown priors or to handle evidence gaps in early-stage models has been advocated. Belief elicitation methods emerged from probability theory and statistics and have found different applications in healthcare [43]. Belief elicitation is used in quite a number of papers implementing headroom analysis or an early-stage health economic model. Specific 
applications of elicitation methods were published in several studies presenting an early health economic model [44-46] or for estimation of headroom [24, 47].

In principle, belief elicitation can be used to estimate unknown probabilities as well as unknown effect sizes. Cao et al. and Kip et al. used probability elicitation to estimate transition probabilities in a health economic model [47]. Haakma et al. used belief elicitation to estimate the likely diagnostic performance of a new imaging device [44]. Different methods have been used to elicit beliefs and the implementation requires a strict protocol, including methods to calibrate the experts. Recently, clear guidelines on the reporting of belief elicitation were published [48]. Another useful resource is available from the University of Sheffield with the Sheffield Elicitation Framework (www. tonyohagan.co.uk/shelf/).

\section{Future Outlook: Use of Early Health Technology Assessment in Value-Based Healthcare}

While this review has mainly illustrated the historical context and some of the more recent work on early HTA, the future outlook is appealing. With increasing pressure on health systems, an increasing consumer demand, an increasing complexity of biomedical $\mathrm{R} \& \mathrm{D}$, and a larger amount of resources spent on product development, a move toward earlier assessments of product's societal and clinical benefits is very valuable [49].

Although the present study has not been able to identify the actual impact of early HTA on companies' portfolio decisions, the increase in empirical early HTA studies suggests that early HTA fills a gap in medical product development. It is hypothesized that, in particular for devices, early HTA may even gain more impact. Craven et al. sent out a survey to SMEs regarding their health economics knowledge and concluded that $60 \%$ of SME participants (mostly company directors or managers, including product or project managers) rated themselves as having either low or no knowledge of health economics prior to the workshops with the remainder professing at least average knowledge [50].

For several reasons, discussed in the remaining sections, early HTA will likely receive more attention in the coming decade, while, at the same time, the paradigm or context for doing such assessments will change. We consider three trends based on the observation that society is increasingly concerned with delivering value for money in a timely and accountable way, including [1] the move towards valuebased healthcare, [2] the dynamics of healthcare pathways, and [3] the personalization of treatment.

\subsection{Value-Based Healthcare}

Most of the work on early HTA is performed under the paradigm that society is willing to pay for additional value generated. This means that, in particular for medical devices, company portfolio decisions and pricing strategies will be based on the added value of a new product instead of a more classic 'cost-plus' mechanism. Carrying out early HTA enables a company to target for a specific added value to society or, alternatively, adapt their pricing strategy to a level that is justified given the added value. A company's product portfolio, likewise, will be evaluated based on the prospect to deliver value to society in addition to strategic and technological competitive advantages. In most of the empirical studies presenting an early health economic model, the assumption is that the QALY is the single metric of value. Yet, the QALY is not used in all jurisdictions as a mechanism to justify resource allocation. Second, it is argued that the QALY does not capture all value components relevant for society and for patients [51-55].

Therefore, alternative methods to measure value have been explored and used such as discrete-choice experiments and MCDA and it is quite easy to see how such preference elicitation models could be used to estimate the relative value of (hypothetical) new technologies [56], or how they can be used to support R\&D teams making decisions based on relative values of the alternative technologies [57].

\subsection{Healthcare Pathways and Real-World Evidence}

Health technology assessment (and thus early HTA) works on the premise that it synthesizes findings from pragmatically designed clinical trials and other data sources to inform health policy. However, if one is interested in using early HTA to understand the added value to the health system, there are two important challenges, i.e., the use of real-world, in addition to trial, data and the appreciation of healthcare pathways.

Although experimental data are reliable and less prone to all sorts of bias, they are also of limited value to evaluate the dynamics in the health system. In particular, observational studies and other big data sources would allow more detailed analysis of health operations, compliance to guidelines, and the dynamic interactions in the system. These data sources may be useful in addition to other registries, with an emphasis on the use of claims and administrative data and electronic medical records. In this regard, several computational approaches are used and explored to mine large data that may also be used in early HTA [58]. 
A second observation is that most early HTA models to date assume a head-to-head comparison of a new medical product to the current best practice. While this has been common practice in HTA and health economic modeling, this approach may not accurately reflect the dynamics of healthcare pathways where patients are subject to a series of diagnostic procedures and treatment sequences or in cases where the availability of services depends on constraints in the healthcare delivery system. For instance, a recent paper analyzing approximately 250 million patients identified that between 10 and $25 \%$ of the patients follow a completely individualized drug treatment pathway [59]. Hence, it may be useful to consider such dynamic treatment sequences for drugs and diagnostics or monitoring technologies in early HTA. Dynamic simulation modeling methods, such as discrete-event simulation and agent-based modeling, may therefore be used to incorporate the complex interactions in the healthcare delivery system, the emergent behavior of the system, and the dynamics of diagnostic and treatment interactions [60-62].

\subsection{Early Health Technology Assessment and Personalized Medicine}

While several good practices for evidence development exist, the current evidence development strategies are unlikely to be sufficient when it comes to personalizing treatment because they are largely based on a standardized comparison of two or more treatments in a well-identified population. As personalized medicine basically challenges the mechanism to build the evidence base because of the uncertainty in the evidence base around specific biomarkers predictive for therapy outcomes, this introduces some very specific challenges for early HTA. For instance, the speedy discovery of new biomarkers and the appropriate targeting of treatment poses a challenge for evidence generation and thus an interesting field for early HTA [63]. The clinical validation and analysis of clinical utility remain difficult and most likely require different statistical methods. Second, the target population may not be well defined in personalized medicine in the first place, and the treatment strategies can be dynamic, sequential, and very specific for the individual. In such cases where standard randomized controlled trials cannot easily be carried out, simulation modeling approaches may be useful but Markov state-transition models may not be sufficient because such models often do not address time-dependent behavior (e.g., changes in response rates over time), often an important feature of personalized medicine $[64,65]$. Large observational studies and databases that contain extensive genomic, phenotype, socioeconomic, clinical, and outcomes data for thousands of patients are potentially useful additions to more commonly used health outcomes data collected in trials and other planned clinical research [66].

\section{Conclusions and Limitations of this Review}

The field of early HTA is emerging as an essential element of medical product and clinical evidence development. Different definitions have been used, but most frequently early HTA is referred to as the use of economic evaluation in early stages of product development mainly to inform industry at the time that investment decisions are made. Although previous studies have found a number of methodologies used in early HTA, such as methods for risk assessment and management of medical product portfolios, most of the recent empirical studies only report an early-stage health economic model. It is therefore recommended to combine early health economic modeling and systems engineering to map technology development scenarios with reference to societal value.

Although the present review was intended to be a scoping review describing the development of early HTA, there are some limitations with regard to the actual studies included in this article. First, different definitions of early HTA have been used and prevent a clear search strategy, which became even more apparent after testing the search strategy and an appropriate set of keywords. In addition, there is most likely a publication bias when it comes to actual published empirical studies because of intellectual property and confidentiality. However, with these limitations in mind, the review provides several recommendations for future research.

Author Contributions All authors contributed to the study. MIJ and MK discussed the objectives and design of the study. MIJ searched the literature, analyzed the data, and was the primary author. $\mathrm{HK}, \mathrm{EF}$, and MK critically reviewed several versions of the manuscript and provided technical assistance.

\section{Compliance with Ethical Standards}

Funding No funding from external sources was received for this work.

Conflict of interest MIJ, HK, EF, and MK have no conflicts of interest directly relevant to the content of this article.

Data sharing The authors declare that the data supporting the findings of this study are available within the article and its supplementary information files.

Open Access This article is distributed under the terms of the Creative Commons Attribution-NonCommercial 4.0 International License (http://creativecommons.org/licenses/by-nc/4.0/), which permits any noncommercial use, distribution, and reproduction in any medium, provided you give appropriate credit to the original author(s) and the source, provide a link to the Creative Commons license, and indicate if changes were made. 


\section{Appendix}

Search (Title and Abstract)—Search on April, 22017

\begin{tabular}{|c|c|c|}
\hline & Medline & Scopus \\
\hline $\begin{array}{l}\text { "Early HTA" OR "Early Health Technology } \\
\text { Assessment" }\end{array}$ & 18 & 16 \\
\hline "Health Technology Assessment" AND "R\&D" & 22 & 20 \\
\hline $\begin{array}{l}\text { "Health Technology Assessment" AND } \\
\text { "product development" }\end{array}$ & 9 & 19 \\
\hline "Early Modelling” AND “R\&D” & 0 & 1 \\
\hline "Early Modelling" AND "HTA" & 0 & 0 \\
\hline $\begin{array}{l}\text { "Early Modelling" AND "product } \\
\text { development" }\end{array}$ & 0 & 1 \\
\hline "HTA" AND "Commercialization" & 2 & 2 \\
\hline "HTA" AND "Product development" & 6 & 14 \\
\hline "HTA" AND "R\&D” & 19 & 28 \\
\hline "Headroom" AND "product development" & 1 & 9 \\
\hline "Headroom" AND "R\&D" & 0 & 0 \\
\hline "Markov model" AND "product development" & 0 & 14 \\
\hline "Markov model" AND "R\&D" & 12 & 11 \\
\hline $\begin{array}{l}\text { "Patient preference" AND "product } \\
\text { development" }\end{array}$ & 2 & 16 \\
\hline "Patient preference" AND "R\&D" & 5 & 3 \\
\hline "Multi-criteria" AND “R\&D” & 1 & 69 \\
\hline "Multi-criteria" AND "product development" & 0 & 170 \\
\hline \# Unique peer-reviewed papers & 65 & 199 \\
\hline \# of unique peer-reviewed papers (2013-2017) & 36 & 134 \\
\hline \# Unique peer-reviewed (2013-2017) & 148 & \\
\hline
\end{tabular}

Empirical studies presenting an illustration of the headroom methodology

12013 Cao Q, Postmus D, Hillege HL, Buskens E. Probability elicitation to inform early health economic evaluations of new medical technologies: a case study in heart failure disease management. Value Health. 2013 Jun; 16(4):529-35. [47]

22015 Chapman AM, Taylor CA, Girling AJ. Early HTA to Inform Medical Device Development Decisions - The Headroom Method. In: XIII Mediterranean Conference on: Springer International Publishing; 2014. pp. 1151-4. (IFMBE Proceedings; vol. 41). [25]

3 Girling A, Lilford R, Cole A, Young T. Headroom approach to device development: current and future directions. Int $\mathrm{J}$ Technol Assess Health Care. 2015 Jan; 31(5):331-8. [24]

42016 Markiewicz K, van Til JA, IJzerman MJ. Commercial viability of medical devices using Headroom and return on investment calculation. Technological Forecasting and Social Change. 112 (November):338-46. [26]

Empirical studies presenting an early health economic model

52013 Retèl VP, Grutters JPC, van Harten WH, Joore MA. Value of research and value of development in early assessments of new medical technologies. Value Health. 2013 Jul;16(5):720-8 [29]

6* Retèl VP, Joore MA, Drukker CA, Bueno-de-Mesquita JM, Knauer M, van Tinteren H, et al. Prospective costeffectiveness analysis of genomic profiling in breast cancer. Eur J Cancer. 2013 Dec;49(18):3773-9. [39]

7

2015 Miq

Koerber F, Rolauffs B, Rogowski W. Early evaluation and value-based pricing of regenerative medicine technologies. Regen Med. 2013 Nov;8(6):747-58. [30]

Miquel-Cases A, Steuten LMG, Retèl VP, van Harten WH. Early stage cost-effectiveness analysis of a BRCA1-like test to detect triple negative breast cancers responsive to high dose alkylating chemotherapy. Breast. 2015 Aug;24(4):397-405. [32]

9

Brandes A, Sinner MF, Kääb S, Rogowski WH. Early decision-analytic modeling - a case study on vascular closure devices. BMC Health Serv Res. 2015 Oct 27;15:486. [31]

102016 de Windt TS, Sorel JC, Vonk LA, Kip MMA, IJzerman MJ, Saris DBF. Early health economic modelling of singlestage cartilage repair. Guiding implementation of technologies in regenerative medicine. J Tissue Eng Regen Med. 2016 Jul 12. [34]

Buisman LR, Luime JJ, Oppe M, Hazes JMW, Rutten-van Mölken MPMH. A five-year model to assess the early cost-effectiveness of new diagnostic tests in the early diagnosis of rheumatoid arthritis. Arthritis Res Ther. 2016 Jun 10;18(1):135. [38]

12* Buisman LR, Rutten-van Mölken MPMH, Postmus D, Luime JJ, Uyl-de Groot CA, Redekop WK. The early bird catches the worm: early cost-effectiveness of new medical tests. Int J Technol Assess Health Care. 2016 Jan;32(12):46-53. [33]

13* Miquel-Cases A, Retèl VP, van Harten WH, Steuten LMG. Decisions on Further Research for Predictive Biomarkers of High-Dose Alkylating Chemotherapy in TripleNegative Breast Cancer: A Value of Information Analysis. Value Health. 2016 Jun;19(4):419-30.

[37]

14 Kolominsky-Rabas PL, Kriza C, Djanatliev A, Meier F, Uffenorde S, Radeleff J, et al. Health Economic Impact of a Pulmonary Artery Pressure Sensor for Heart Failure Telemonitoring: A Dynamic Simulation. Telemedicine and e-Health. 2016 Oct;22(10):798-808.

[36]

15 Luime JJ, Buisman LR, Oppe M, Hazes JMW, Rutten-van Mölken MPMH. Cost-Effectiveness Model for Evaluating New Diagnostic Tests in the Evaluation of Patients With Inflammatory Arthritis at Risk of Having Rheumatoid Arthritis. Arthritis Care Res (Hoboken). 2016 Jul;68(7):927-35. [35]

16 Kip MMA, Steuten LMG, Koffijberg H, IJzerman MJ, Kusters R. Using expert elicitation to estimate the potential impact of improved diagnostic performance of laboratory tests: a case study on rapid discharge of suspected non-ST elevation myocardial infarction patients. J Eval Clin Pract. 2016 Oct 19. [45]

\footnotetext{
*Excluded from further review (see text for reason)
} 
Empirical studies presenting a stakeholder elicitation study or using MCDA for decision support

172014 Haakma W, Steuten LMG, Bojke L, IJzerman MJ. Belief Elicitation to Populate Health Economic Models of Medical Diagnostic Devices in Development. Appl Health Econ Health Policy. 2014 Mar 13;12(3):327-34. [44] IJzerman MJ. Public stated preferences and predicted uptake for genome-based colorectal cancer screening. BMC Med Inform Decis Mak. 2014 Mar 19;14(1):18. [56]

192015 de Graaf G, Postmus D, Buskens E. Using Multicriteria Decision Analysis to Support Research Priority Setting in Biomedical Translational Research Projects. BioMed Research International. 2015;2015(12):1-9. [67]

202016 Middelkamp HHT, van der Meer AD, Hummel JM, Stamatialis DF, Mummery CL, IJzerman MJ: Organson-Chips in Drug Development: The Importance of Involving Stakeholders in Early Health Technology Assessment. Applied In Vitro Toxicology. 2016 Feb 19;:aivt.2015.0029.

[42]

21 Fermont JM, Douw KHP, Vondeling H, IJzerman MJ. Ranking medical innovations according to perceived health benefit. Health Policy and Technology. 2016; 5(2): 156-165

[68]

22 Joosten SEP, Retèl VP, Coupé VMH, van den Heuvel MM, Van Harten WH. Scenario drafting for early technology assessment of next generation sequencing in clinical oncology. BMC Cancer. 2016 Feb 6;16:66. [69]
Groothuis-Oudshoorn CGM, Fermont JM, van Til JA,

Excluded papers (no empirical studies, demonstration, conceptual papers)

252014 Ciani O, Jommi C. The role of health technology assessment bodies in shaping drug development. Drug Des Devel Ther. 2014;8:2273-81. [20]

Pham B, Tu HAT, Han D, Pechlivanoglou P, Miller F, Rac V, et al. Early economic evaluation of emerging health technologies: protocol of a systematic review. Syst Rev. 2014;3:81.

[72]

27 Markiewicz K, van Til JA, IJzerman MJ. Medical devices early assessment methods: systematic literature review. Int J Technol Assess Health Care. 2014 May 7; $1-10$ [21]

Lal JA, Morré SA, Brand A. The overarching framework of translation and integration into healthcare: a case for the LAL model. Personalized Medicine. 2014 Jan;11(1):41-62.

[73]

29 Djanatliev A, Kolominsky-Rabas P, Hofmann BM, Aisenbrey A, German R. System Dynamics and AgentBased Simulation for Prospective Health Technology Assessments. In: Simulation and Modeling Methodologies. Springer International Publishing; 2014. pp. 85-96. (Advances in Intelligent Systems and Computing; vol. 256). [40]

30 Steuten LMG, Ramsey SD. Improving early cycle economic evaluation of diagnostic technologies. Expert Rev Pharmacoeconomics Outcomes Res. 2014 Aug;14(4):491-8

[74]

312015 Jönsson B. Bringing in health technology assessment and cost-effectiveness considerations at an early stage of drug development. Mol Oncol. 2015 May;9(5):1025-33. [75]

32 Kolominsky-Rabas PL, Djanatliev A, Wahlster P, Gantner-Bär M, Hofmann B, German R, et al. Technology foresight for medical device development through hybrid simulation: The ProHTA Project. Technological Forecasting and Social Change. 2015 Aug;97:105-14.

papers)

232013 McCall MJ, Williams DJ. Developing Cell Therapies: Enabling cost prediction by value systems modeling to manage developmental risk. ProQuest. J. of Commercial Biotechnology. 2013.

[70]

24 Pecchia L, Craven MP. Early stage Health Technology Assessment (HTA) of biomedical devices. The MATCH experience. In: World Congress on Medical Physics and Engineering. Berlin, Heidelberg: Springer Berlin Heidelberg; 2013. pp. 1525-8. (IFMBE Proceedings; vol. 39).

\section{[71]}

[62]

33 Levin L. Early Evaluation of New Health Technologies: The case for Premarket studies that harmonize regulatory and coverage perspectives. Int $\mathrm{J}$ Technol Assess Health Care. 2015 Jan;31(4):207-9. [15] 
Excluded papers (no empirical studies, demonstration, conceptual papers)

342016 Steuten LMG. Early Stage Health Technology Assessment for Precision Biomarkers in Oral Health and Systems Medicine. OMICS. 2016 Jan;20(1):30-5. [76]

Luime JJ, Buisman LR, Oppe M, Hazes JMW, Ruttenvan Mölken MPMH. Cost-Effectiveness Model for Evaluating New Diagnostic Tests in the Evaluation of Patients With Inflammatory Arthritis at Risk of Having Rheumatoid Arthritis. Arthritis Care Res (Hoboken). 2016 Jul;68(7):927-35. [35]

Huygens SA, Rutten-van Mölken MPMH, Bekkers JA, Bogers AJJC, Bouten CVC, Chamuleau SAJ, et al. Conceptual model for early health technology assessment of current and novel heart valve interventions. Open Heart. 2016 Oct 14;3(2):e000500 [46]

372017 Miquel-Cases A, Schouten PC, Steuten LMG, Retèl VP, Linn SC, van Harten WH. (Very) Early technology assessment and translation of predictive biomarkers in breast cancer. Cancer Treat Rev. 2017 Jan;52:117-27. [63]

Van Harten WH, Retèl VP. Innovations that reach the patient: early health technology assessment and improving the chances of coverage and implementation. Ecancermedicalscience. 2016;10:683. [77]

\section{References}

1. Mauskopf J, Schulman K, Bell L, Glick H. A strategy for collecting pharmacoeconomic data during phase II/III clinical trials. Pharmacoeconomics. 1996;9(3):264-77.

2. Sculpher M, Drummond M, Buxton M. The iterative use of economic evaluation as part of the process of health technology assessment. J Health Serv Res Policy. 1997;2(1):26-30.

3. Grabowski H. The effect of pharmacoeconomics on company research and development decisions. Pharmacoeconomics. 1997;11(5):389-97.

4. Terrés CR. Pharmacoeconomic analysis in new drug development: a pragmatic approach to efficiency studies. Clin Res Regul Aff. 1998;15(3-4):209-23.

5. Dong H, Buxton M. Early assessment of the likely cost-effectiveness of a new technology: a Markov model with probabilistic sensitivity analysis of computer-assisted total knee replacement. Int J Technol Assess Health Care. 2006;22(2):191-202.

6. van Til JA, Renzenbrink GJ, Groothuis-Oudshoorn CGM, IJzerman MJ. A preliminary economic evaluation of percutaneous neuromuscular electrical stimulation in the treatment of hemiplegic shoulder pain. Disabil Rehabil. 2006;28(10):645-51.

7. Hjelmgren J, Ghatnekar O, Reimer J, et al. Estimating the value of novel interventions for Parkinson's disease: an early decisionmaking model with application to dopamine cell replacement. Parkinsonism Relat Disord. 2006;12(7):443-52.

8. Hartz S, John J. Contribution of economic evaluation to decision making in early phases of product development: a methodological and empirical review. Int $\mathbf{J}$ Technol Assess Health Care. 2008;24(4):465-72.
9. Clemens K, Garrison LP, Jones A, Macdonald F. Strategic use of pharmacoeconomic research in early drug development and global pricing. Pharmacoeconomics. 1993;4(5):315-22.

10. Miller P. Role of pharmacoeconomic analysis in R\&D decision making: when, where, how? Pharmacoeconomics. 2005;23(1):1-12.

11. Vallejo-Torres L, Steuten LMG, Buxton MJ, et al. Integrating health economics modeling in the product development cycle of medical devices: a Bayesian approach. Int J Technol Assess Health Care. 2008;24(4):459-64.

12. Pietzsch JB, Paté-Cornell ME. Early technology assessment of new medical devices. Int $\mathrm{J}$ Technol Assess Health Care. 2008;24(1):36-44.

13. IJzerman MJ, Steuten LMG. Early assessment of medical technologies to inform product development and market access. Appl Health Econ Health Policy. 2011;9(5):331-47.

14. Rogowski WH, John J, IJzerman MJ. Translational health economics. In: Sheffler RM, editor. World scientific handbook of global health economics and public policy. 3rd ed. Singapore: World Scientific Publishing Company; 2013.

15. Levin L. Early evaluation of new health technologies: the case for premarket studies that harmonize regulatory and coverage perspectives. Int J Technol Assess Health Care. 2015;31(4):207-9.

16. Annemans L, Genesté B, Jolain B. Early modelling for assessing health and economic outcomes of drug therapy. Value Health. 2000;3(6):427-34.

17. Dimasi JA, Caglarcan E, Wood-Armany M. Emerging role of pharmacoeconomics in the research and development decisionmaking process. Pharmacoeconomics. 2001;19(7):753-66.

18. Fenwick E. An iterative Bayesian approach to health technology assessment: application to a policy of preoperative optimization for patients undergoing major elective surgery. Med Decis Mak. 2006;26(5):480-96.

19. De Pinho Campos K, Norman CD, Jadad AR. Product development public-private partnerships for public health: a systematic review using qualitative data. Soc Sci Med. 2011;73(7):986-94.

20. Ciani O, Jommi C. The role of health technology assessment bodies in shaping drug development. Drug Des Devel Ther. 2014;8:2273-81.

21. Markiewicz K, van Til JA, IJzerman MJ. Medical devices early assessment methods: systematic literature review. Int J Technol Assess Health Care. 2014;30(2):137-46.

22. Retèl VP, Hummel MJM, van Harten WH. Review on early technology assessments of nanotechnologies in oncology. Mol Oncol. 2009;3(5-6):394-401.

23. Cosh E, Girling A, Lilford R. Investing in new medical technologies: a decision framework. J Commer Biotechnol. 2007;13(4):263-71.

24. Girling A, Lilford R, Cole A, Young T. Headroom approach to device development: current and future directions. Int J Technol Assess Health Care. 2015;31(5):331-8.

25. Chapman AM, Taylor CA, Girling AJ. Early HTA to inform medical device development decisions: the headroom method. In: XIII Mediterranean Conference on Biomedical Engineering and Computing (IFMBE Proceedings; vol. 41). Seville, Spain: Springer International Publishing; 2013. p. 1151-4.

26. Markiewicz K, van Til JA, IJzerman MJ. Commercial viability of medical devices using headroom and return on investment calculation. Technol Forecast Soc Change. 2016;112(Nov):338-46.

27. McAteer H, Cosh E, Freeman G, et al. Cost-effectiveness analysis at the development phase of a potential health technology: examples based on tissue engineering of bladder and urethra. J Tissue Eng Regen Med. 2007;1(5):343-9.

28. Hartmann M. Application of real options analysis for pharmaceutical R\&D project valuation: empirical results from a survey. Res Policy. 2006;35:343-54. 
29. Retèl VP, Grutters JPC, van Harten WH, Joore MA. Value of research and value of development in early assessments of new medical technologies. Value Health. 2013;16(5):720-8.

30. Koerber F, Rolauffs B, Rogowski W. Early evaluation and valuebased pricing of regenerative medicine technologies. Regen Med. 2013;8(6):747-58.

31. Brandes A, Sinner MF, Kääb S, Rogowski WH. Early decisionanalytic modeling: a case study on vascular closure devices. BMC Health Serv Res. 2015;27(15):486.

32. Miquel-Cases A, Steuten LMG, Retèl VP, van Harten WH. Early stage cost-effectiveness analysis of a BRCA1-like test to detect triple negative breast cancers responsive to high dose alkylating chemotherapy. Breast. 2015;24(4):397-405.

33. Buisman LR, Rutten-van Mölken MPMH, Postmus D, et al. The early bird catches the worm: early cost-effectiveness of new medical tests. Int $\mathrm{J}$ Technol Assess Health Care. 2016;32(1-2):46-53.

34. de Windt TS, Sorel JC, Vonk LA, et al. Early health economic modelling of single-stage cartilage repair: guiding implementation of technologies in regenerative medicine. J Tissue Eng Regen Med. 2016. doi:10.1002/term.2197 (Epub ahead of print).

35. Luime JJ, Buisman LR, Oppe M, et al. Cost-effectiveness model for evaluating new diagnostic tests in the evaluation of patients with inflammatory arthritis at risk of having rheumatoid arthritis. Arthritis Care Res (Hoboken). 2016;68(7):927-35.

36. Kolominsky-Rabas PL, Kriza C, Djanatliev A, et al. Health economic impact of a pulmonary artery pressure sensor for heart failure telemonitoring: a dynamic simulation. Telemed J E Health. 2016;22(10):798-808.

37. Miquel-Cases A, Retèl VP, van Harten WH, Steuten LMG. Decisions on further research for predictive biomarkers of highdose alkylating chemotherapy in triple-negative breast cancer: a value of information analysis. Value Health. 2016;19(4):419-30.

38. Buisman LR, Luime JJ, Oppe M, et al. A five-year model to assess the early cost-effectiveness of new diagnostic tests in the early diagnosis of rheumatoid arthritis. Arthritis Res Ther. 2016;18(1):135.

39. Retèl VP, Joore MA, Drukker CA, et al. Prospective cost-effectiveness analysis of genomic profiling in breast cancer. Eur $\mathbf{J}$ Cancer. 2013;49(18):3773-9.

40. Djanatliev A, Kolominsky-Rabas P, Hofmann BM, et al. System dynamics and agent-based simulation for prospective health technology assessments. Advances Intelligent Syst Comput. 2014;256:85-96.

41. Thokala P, Devlin N, Marsh K, et al. Multiple criteria decision analysis for health care decision making: an introduction. Report 1 of the ISPOR MCDA Emerging Good Practices Task Force. Value Health. 2016;19(1):1-13.

42. Middelkamp HHT, van der Meer AD, Hummel JM, et al. Organson-chips in drug development: the importance of involving stakeholders in early health technology assessment. Appl In Vitro Toxicol. 2016;2(2):74-81

43. O'Hagan A. Eliciting expert beliefs in substantial practical applications. Statistician. 1998;47(1):21-35.

44. Haakma W, Steuten LMG, Bojke L, IJzerman MJ. Belief elicitation to populate health economic models of medical diagnostic devices in development. Appl Health Econ Health Policy. 2014;12(3):327-34.

45. Kip MMA, Steuten LMG, Koffijberg H, IJzerman MJ, Kusters R. Using expert elicitation to estimate the potential impact of improved diagnostic performance of laboratory tests: a case study on rapid discharge of suspected non-ST elevation myocardial infarction patients. J Eval Clin Pract. 2016. doi:10.1111/jep. 12626.
46. Huygens SA, Rutten-van Mölken MPMH, Bekkers JA, et al. Conceptual model for early health technology assessment of current and novel heart valve interventions. Open Heart. 2016;3(2):e000500.

47. Cao Q, Postmus D, Hillege HL, Buskens E. Probability elicitation to inform early health economic evaluations of new medical technologies: a case study in heart failure disease management. Value Health. 2013;16(4):529-35.

48. Iglesias CP, Thompson A, Rogowski WH, Payne K. Reporting guidelines for the use of expert judgement in model-based economic evaluations. Pharmacoeconomics. 2016;34(11):1161-72.

49. Stewart DJ, Batist G, Kantarjian HM, et al. The urgent need for clinical research reform to permit faster, less expensive access to new therapies for lethal diseases. Clin Cancer Res. 2015;21(20):4561-8.

50. Craven MP, Allsop MJ, Morgan SP, Martin JL. Engaging with economic evaluation methods: insights from small and medium enterprises in the UK medical devices industry after training workshops. Health Res Policy Sys. 2012;3(10):29.

51. Carrera P, IJzerman MJ. Are current ICER thresholds outdated? Valuing medicines in the era of personalized healthcare. Expert Rev Pharmacoecon Outcomes Res. 2016;16(4):435-7.

52. Ryan M, Kinghorn P, Entwistle VA, Francis JJ. Valuing patients' experiences of healthcare processes: towards broader applications of existing methods. Soc Sci Med. 2014;106:194-203.

53. Drummond M, Towse A. Orphan drugs policies: a suitable case for treatment. Eur J Health Econ. 2014;15(4):335-40.

54. Angelis A, Kanavos P. Value-based assessment of new medical technologies: towards a robust methodological framework for the application of multiple criteria decision analysis in the context of health technology assessment. Pharmacoeconomics. 2016;34(5):435-46.

55. Linley WG, Hughes DA. Societal views on NICE, cancer drugs fund and value-based pricing criteria for prioritising medicines: a cross-sectional survey of 4118 adults in Great Britain. Health Econ. 2013;22(8):948-64.

56. Groothuis-Oudshoorn CGM, Fermont JM, van Til JA, IJzerman MJ. Public stated preferences and predicted uptake for genomebased colorectal cancer screening. BMC Med Inform Decis Mak. 2014;14(1): 18

57. Miloslavsky EM, Naden RP, Bijlsma JWJ, et al. Development of a Glucocorticoid Toxicity Index (GTI) using multicriteria decision analysis. Ann Rheum Dis. 2017;76(3):543-6.

58. Crown WH. Potential application of machine learning in health outcomes research and some statistical cautions. Value Health. 2015;18(2):137-40.

59. Hripcsak G, Ryan PB, Duke JD, et al. Characterizing treatment pathways at scale using the OHDSI network. Proc Natl Acad Sci USA. 2016;113(27):7329-36.

60. Marshall DA, Burgos-Liz L, IJzerman MJ, et al. Applying dynamic simulation modeling methods in health care delivery research: the SIMULATE checklist. Report of the ISPOR Simulation Modeling Emerging Good Practices Task Force. Value Health. 2015;18(1):5-16.

61. Marshall DA, Burgos-Liz L, IJzerman MJ, et al. Selecting a dynamic simulation modeling method for health care delivery research: part 2. Report of the ISPOR Dynamic Simulation Modeling Emerging Good Practices Task Force. Value Health. 2015;18(2):147-60.

62. Kolominsky-Rabas PL, Djanatliev A, Wahlster P, et al. Technology foresight for medical device development through hybrid simulation: the ProHTA Project. Technol Forecast Soc Change. 2015;97:105-14.

63. Miquel-Cases A, Schouten PC, Steuten LMG, et al. (Very) Early technology assessment and translation of predictive biomarkers in breast cancer. Cancer Treat Rev. 2017;52:117-27. 
64. IJzerman MJ, Manca A, Keizer J, Ramsey SD. Implementing comparative effectiveness research in personalized medicine applications in oncology: current and future perspectives. Comp Eff Res. 2015;5:65-72.

65. Degeling K, Koffijberg H, IJzerman MJ. A systematic review and checklist presenting the main challenges for health economic modeling in personalized medicine: towards implementing patient-level models. Expert Rev Pharmacoecon Outcomes Res. 2017;17(1):17-25.

66. Collins B. Big data and health economics: strengths, weaknesses, opportunities and threats. Pharmacoeconomics. 2016;34(2):101-6.

67. de Graaf G, Postmus D, Buskens E. Using multicriteria decision analysis to support research priority setting in biomedical translational research projects. BioMed Res Int. 2015;2015(12):1-9.

68. Fermont JM, Douw KHP, Vondeling H, Ijzerman MJ. Ranking medical innovations according to perceived health benefit. Health Policy Technol. 2016;5(2):156-65.

69. Joosten SEP, Retèl VP, Coupé VMH, et al. Scenario drafting for early technology assessment of next generation sequencing in clinical oncology. BMC Cancer. 2016;6(16):66.

70. McCall MJ, Williams DJ. Developing cell therapies: enabling cost prediction by value systems modeling to manage developmental risk. J Commercial Biotechnol. 2013;19(2):27-39
71. Pecchia L, Craven MP. Early stage health technology assessment (HTA) of biomedical devices: the MATCH experience. In: World Congress on Medical Physics and Biomedical Engineering (IFMBE Proceedings; vol. 39). Berlin: Springer; 2013. p. 1525-8.

72. Pham B, Tu HAT, Han D, et al. Early economic evaluation of emerging health technologies: protocol of a systematic review. Syst Rev. 2014;3:81.

73. Lal JA, Morré SA, Brand A. The overarching framework of translation and integration into healthcare: a case for the LAL model. Personal Med. 2014;11(1):41-62.

74. Steuten LMG, Ramsey SD. Improving early cycle economic evaluation of diagnostic technologies. Expert Rev Pharmacoecon Outcomes Res. 2014;14(4):491-8.

75. Jönsson B. Bringing in health technology assessment and costeffectiveness considerations at an early stage of drug development. Mol Oncol. 2015;9(5):1025-33.

76. Steuten LMG. Early stage health technology assessment for precision biomarkers in oral health and systems medicine. OMICS. 2016;20(1):30-5.

77. Van Harten WH, Retèl VP. Innovations that reach the patient: early health technology assessment and improving the chances of coverage and implementation. Ecancermedicalscience. 2016;10:683. 